\title{
Economic Waves: The Effect of the U.S. Economy on the World Economy
}

\author{
Mario Arturo Ruiz Estrada ${ }^{1}$
}

ABSTRACT

\begin{abstract}
This paper models the inter-connections between the U.S. economy and five major economic regions in the world, namely, Japan, China, ASEAN, Latin America, and the European Union, using an inter-linkage coordinate space. This space is represented graphically, with the U.S. economy placed in the center and the connected economic regions plotted along rays (axes) that are drawn from the center, each of which can have as many windows as are required at the predetermined perimeter levels. Using this model, this paper evaluates whether and how an economic recession or financial crisis in the U.S. economy can simultaneously affect the five aforementioned economic regions. Finally, this paper proposes the use of computer graphical animation to provide a visual representation of the concomitant effect of these economic waves in the same graphical space.
\end{abstract}

KEY WORDS: $\quad$ econographicology; euclidean geometry; economic teaching

JEL Classification: B40; B41

1 University of Malaya, Malaysia

\section{The Evolution of Graphical Modeling in Economics from 2-Dimensional to Multi-Dimensional}

Academics and scholars have long been limited to 2-dimensional graphical modeling (Shchepin, 1976), but advancement in computer technology now allows the development of multi-dimensional graphical models. This paper illustrates a novel type of economic modeling for studying market behavior as a whole. This method combines new multidimensional graphical modeling tools with to display the propagation of effects in real time. Two-Dimensional graphical models are only able to display historical and forecasting data

Correspondence concerning this article should be addressed to: Mario Arturo Ruiz Estrada, University of Malaya, Faculty of Economics and Administration, 50603 Kuala Lumpur, MALAYSIA. T: +60379673728 Email: marioruiz@um.edu.my in the same graphical space within a limited space of time. In contrast, multidimensional real-time graphical modeling can display all possible changes among a large number of variables. By producing a multidimensional graph that displays simultaneous changes in many variables, this type of modeling allows observers to clearly see cause and effect among the different variables. Here, we demonstrate that 2-dimensional $(\mathrm{X}, \mathrm{Y})$ and 3-dimensional space $(\mathrm{X}, \mathrm{Y}, \mathrm{Z})$ can only illustrate a micro-slice of complex and dynamic economic phenomena. The hypothesis of this paper is that 2-dimensional and 3-dimensional spaces are a micro-slice of the huge mega-space or universe of a fixed period of time and common space. To test this hypothesis, this paper applies an alternative, multi-dimensional graphical modeling method called "Inter-Linkage Coordinate Space" to a set of economic variables. Economists have long attempted to visualize simple (static) or complex 
(dynamic) economic phenomena across a specific period of time in the same graphical space through the application of 2-dimensional $(\mathrm{X}, \mathrm{Y})$ or 3-dimensional spaces $(\mathrm{X}, \mathrm{Y}, \mathrm{Z})$. Given their widespread use, this paper also investigates why economists continue to use 2-dimensional $(\mathrm{X}, \mathrm{Y})$ or 3-dimensional $(\mathrm{X}, \mathrm{Y}, \mathrm{Z})$ graphical representations of complex and dynamic economic phenomena; some possible explanations are as follows:

- The application of 2-dimensional and 3-Dimensional spaces in the economic graphical analysis is simply an ingrained tradition.

- 2-dimensional and 3-Dimensional spaces are simple and easy methods for visualizing basic trends or values in the same graphical space.

- Alternative and suitable multi-dimensional graphical models are not readily available.

The main hypothesis of this paper is that 2-dimensional and 3-dimensional spaces are inadequate for modeling complex economic behavior. The real world is constantly changing along nearly unlimited measures, spaces and times (Inselberg and Dimsdale, 1994). Therefore, this paper proposes a type of multi-dimensional economic modeling that can dynamically display a large number of variables in the same graphical space in both real time and slow motion and that can be used to study the behavior of complex and dynamic economic phenomena.

\section{An Introduction to the Inter- Linkage Coordinate Space}

The inter-linkage coordinate space (Ruiz Estrada, 2011a) is formed by an infinite number of general axes $\left(A_{0}, A_{1}, \ldots, A_{n} \ldots\right)$, perimeter levels $\left(L_{0}, L_{1}, \ldots\right.$, $\mathrm{L}_{\mathrm{n}} \ldots$ ) and window refractions $\left(\mathrm{W}_{0}, \mathrm{~W}_{1, \ldots,}, \mathrm{W}_{\mathrm{n} . . .}\right)$ (see Figure 1 and Prototype 1). Each window refraction is produced by joining its sub- $\mathrm{x}$ axis $\left(\mathrm{X}_{\mathrm{A}-\mathrm{L}}\right)$ with its sub-y axis $\left(\mathrm{Y}_{\mathrm{A}-\mathrm{L}}\right)$; therefore, each window refractions $\left(\mathrm{W}_{0}, \mathrm{~W}_{1 \ldots}, \mathrm{W}_{\mathrm{n} . . .}\right)$ has its own coordinate space $\left(X_{A-L}, Y_{A-L}\right)$. All window refractions on the same general axis $\left(A_{0}, A_{1}, \ldots, A_{n} \ldots\right)$ are joined together under the application of the inter-linkage connectivity of windows refraction, represented by “®”; this inter-connects all window refractions $\left(\mathrm{W}_{0}\right.$, $\left.\mathrm{W}_{1}, \ldots, \mathrm{W}_{\mathrm{n}} \ldots\right)$ on the same general axis $\left(\mathrm{A}_{0}, \mathrm{~A}_{1}, \ldots\right.$, $\left.A_{n} \ldots\right)$ but in different perimeter levels $\left(L_{0}, L_{1}, \ldots, L_{n}\right.$ ...). The inter-linkage coordinate system is represented by Expression 1:
(1.) Perimeter level $P_{0}{ }^{\circledR}$ Perimeter level $P_{1}{ }^{\circledR} \ldots{ }^{\circledR}$ Perimeter level $\mathrm{P}_{\mathrm{n}}$ General Axis $0\left(A_{0}\right): W_{0-0}=\left(x_{0-0,} y_{0-0}\right) \circledast W_{0-1}=\left(x_{0-1,1} y_{0-1}\right)$ ( .... $W_{0-\infty}=\left(x_{0-\infty,} y_{0-\infty}\right)$

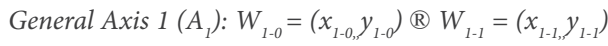
(B... ${ }^{\circledR} W_{1-\infty}=\left(x_{1-\infty,} y_{1-\infty}\right)$

General Axis $2\left(A_{2}\right): W_{2-0}=\left(x_{2-0,}, y_{2-0}\right) \circledast W_{2-1}=\left(x_{2-1,1} y_{2-1}\right)$ (B... ${ }^{\circledR} W_{2-\infty}=\left(x_{2-\infty}, y_{2-\infty}\right)$

General Axis $3\left(A_{3}\right): W_{3-0}=\left(x_{3-0,0} y_{3-0}\right) \circledast W_{3-1}=\left(x_{3-1, n}, y_{3-1}\right)$ (®)..® $W_{3-\infty}=\left(x_{3-\infty}, y_{3-\infty}\right)$

General Axis $4\left(A_{4}\right): W_{4-0}=\left(x_{4-0,0} y_{4-0}\right) \circledast W_{4-1}=\left(x_{4-1, n}, y_{4-1}\right)$ (B... ${ }^{\circledR} W_{4-\infty}=\left(x_{4-\infty}, y_{4-\infty}\right)$

General Axis $5\left(A_{5}\right): W_{5-0}=\left(x_{5-0,0} y_{5-0}\right) \circledast W_{5-1}=\left(x_{5-}\right.$ $\left.{ }_{1, n} y_{5-1}\right)$ (...® $W_{5-\infty}=\left(x_{5-\infty,}, y_{5-\infty)}\right.$

General Axis $n\left(A_{\infty}\right): W_{\infty-0}=\left(x_{\infty-0,0} y_{\infty-0}\right) \circledR$ ... $W_{\infty-\infty}=\left(x_{\infty-\infty,}, y_{\infty-\infty}\right)$

The inter-linkage coordinate space is available to fix a large number of different functions located in different windows refraction $\left(\mathrm{W}_{0}, \mathrm{~W}_{1}, \ldots, \mathrm{W}_{\mathrm{n}} \ldots\right)$, perimeter levels $\left(\mathrm{L}_{1}, \mathrm{~L}_{2}, \ldots, \mathrm{L}_{\mathrm{n}} \ldots\right)$ and general axes $\left(\mathrm{A}_{1}, \mathrm{~A}_{2}, \ldots, \mathrm{A}_{\mathrm{n}} \ldots\right)$ (see Expression 2):

(2.) Perimeter level $\mathrm{P}_{0}{ }^{\oplus}$ Perimeter level $\mathrm{P}_{1}{ }^{\circledR} \ldots{ }^{\oplus}$ Perimeter level $\mathrm{P}_{\mathrm{n}}$

General Axis 0 (A $\left.A_{0}\right): y_{0-0}=f\left(x_{0-0}\right)$ \& $y_{0-1}=f\left(x_{0-1}\right)$ (B....... $y_{0-\infty}=f\left(x_{0-\infty}\right)$

General Axis $1\left(A_{1}\right)$ : $y_{1-0}=f\left(x_{1-0}\right)$ \& $y_{1-1}=f\left(x_{1-1}\right)$ ( ....... $y_{1-\infty}=f\left(x_{1-\infty}\right)$

General Axis $2\left(A_{2}\right)$ : $y_{2-0}=f\left(x_{2-0}\right)$ ® $y_{2-1}=f\left(x_{2-1}\right)$ ( ......... $y_{2-\infty}=f\left(x_{2-\infty}\right)$

General Axis $3\left(A_{3}\right): y_{3-0}=f\left(x_{3-0}\right) \circledast y_{3-1}=f\left(x_{3-1}\right) \circledast \ldots \ldots .($ $y_{3-\infty}=f\left(x_{3-\infty}\right)$

General Axis $4\left(A_{4}\right): y_{4-0}=f\left(x_{4-0}\right)$ ( $y_{4-1}=f\left(x_{4-1}\right)$ (........ $y_{4-\infty}=f\left(x_{4-\infty}\right)$

General Axis $5\left(A_{5}\right): y_{5-0}=f\left(x_{5-0}\right) \circledast y_{5-1}=f\left(x_{5-1}\right)$ (R). (B) $y_{5-\infty}=f\left(x_{5-\infty}\right)$

General Axis $n\left(A_{\infty}\right): y_{\infty-0}=f\left(x_{\infty-0}\right) \mathbb{B}$ ( 


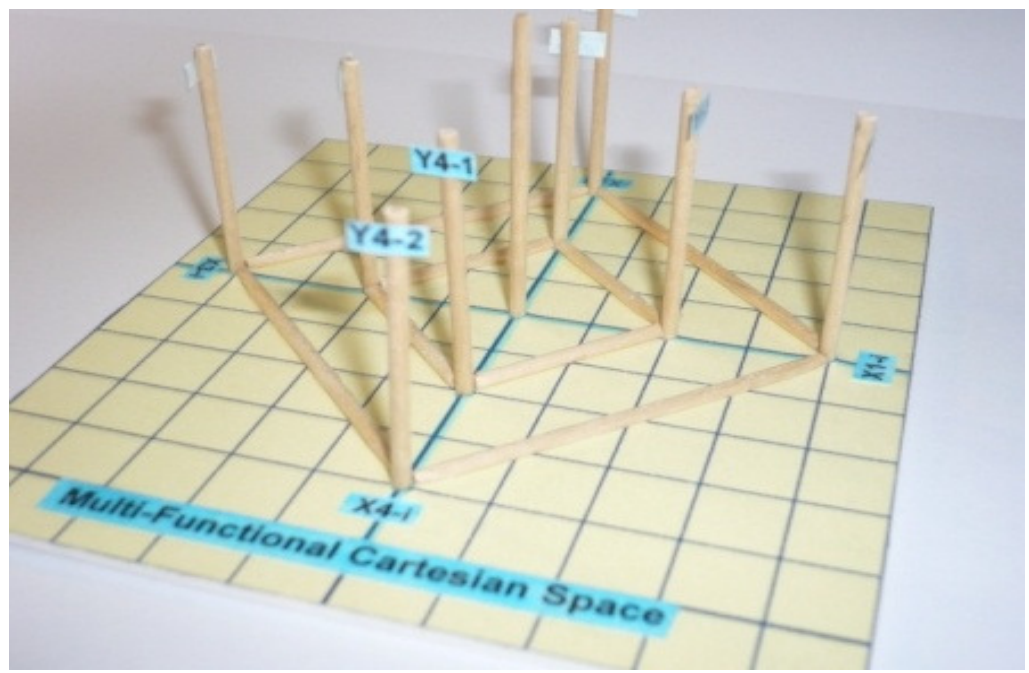

Prototype 1. The Inter-Linkage Coordinate Space

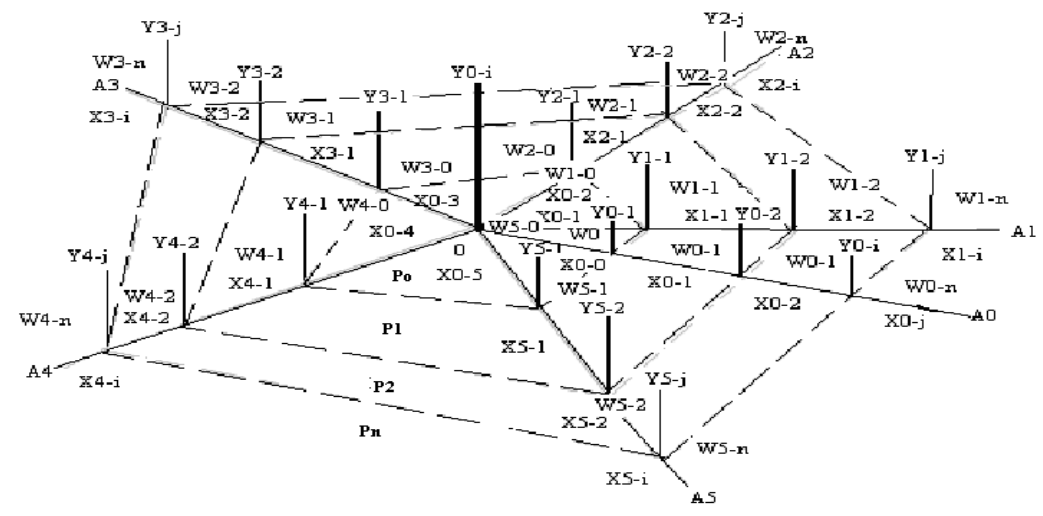

Figure 1. The Inter-Linkage Coordinate Space

\section{Economic Waves}

In this section, we describe economic waves, which are generated from a large surface plotted in the same graphical space. The large surface is formed by different parts that represent different markets (countries/ regions), all of which are connected directly to a single epicenter. For the case studied in this paper, this epicenter is fixed by the GDP growth rate of the U.S. The GDP growth rate of the U.S. economy can experience dramatic, uncontrolled and non-logical changes at any time, such as expansion, contraction or stagnation (Ruiz Estrada \& Yap, 2013; Ruiz, Yap, \& Park, 2014). An abrupt negative fall of the GDP growth rate in the U.S. economy can generate large negative effects 
Table 1. Windows Refraction

\begin{tabular}{|c|c|c|}
\hline Country 1 or Region 1: & Country 2 or Region 2: & Country 3 or Region 3: \\
\hline Windows Refraction: & Windows Refraction: & Windows Refraction: \\
\hline $\begin{array}{l}\text { Windows Refraction } 1 \text { 步Windows } \\
\text { Refraction } 2 \text { 步Windows Refraction } \\
3 \text { 步... Windows Refraction } \infty . .\end{array}$ & $\begin{array}{c}\text { Windows Refraction } 1 \text { 步Windows } \\
\text { Refraction } 2 \text { 步Windows Refraction } \\
3 \text { t } 5 \text {... Windows Refraction } \infty . .\end{array}$ & $\begin{array}{l}\text { Windows Refraction } 1 \text { 尘Windows } \\
\text { Refraction } 2 \text { 步Windows Refraction } \\
3 \text { 少... Windows Refraction } \infty . .\end{array}$ \\
\hline Country 4 or Region 4: & Country 5 or Region 5: & Country $\infty$ or Region $\infty:$ \\
\hline Windows Refraction: & Windows Refraction: & Windows Refraction: \\
\hline $\begin{array}{c}\text { Windows Refraction } 1 \text { 少Windows } \\
\text { Refraction } 2 \text { 少Windows Refraction } \\
3 \frac{1}{7} \text {... Windows Refraction } \infty . . .\end{array}$ & $\begin{array}{c}\text { Windows Refraction } 1 \text { 少Windows } \\
\text { Refraction } 2 \mathbb{t} \text { Windows Refraction } \\
3 \frac{1}{7} \text {... Windows Refraction } \infty . .\end{array}$ & $\begin{array}{c}\text { Windows Refraction } 1 \text { thWindows } \\
\text { Refraction } 2 \text { WWindows Refraction } \\
3 \\
3 \neq \text {.... Windows Refraction } \infty . . .\end{array}$ \\
\hline
\end{tabular}

at different levels in different markets simultaneously because of the investment mobility and large amount of international trade between the U.S. economy and different countries/regions.

This paper assumes that each market (country/region) has a large number of windows refraction (or quadrants), each of which is formed by its X-axis, which represents time (days, weeks, months, years and decades), and its Y-axis, which represents the main variable(s) under consideration. The main variables in our model of each window refraction for different market(s) are the growth rates $\mathrm{GDP}_{\mathrm{US}}$, exports (X), foreign direct investment (FDI), the stock market (SM) and unemployment (U). Thus, each market (country/ region) possesses five windows refraction within the same coordinate space (see Table 1 and Figure 2). Second, we assume that the economic wave in each market (country/region) propagate at different speeds and sizes. The size and speed of the economic waves depend on uncontrolled forces of the market, such as economic speculation(s), economic bubbles and imaginary markets (Issing, 2011). The main objective in modeling these economic waves is to evaluate the global negative impact that comes from a deep economic recession in the U.S. economy. To do so, we use multi-dimensional graphical modeling that can illustrate the movement of economic waves in real time. Basically, the multi-dimensional graphical animation technique (Ruiz Estrada, 2007; 2012) allows us to ob- serve the effects of a possible deep economic recession in the U.S. economy through the generation of economic waves in different markets (countries/regions) and, at the same time, gauge the level of dependency and vulnerability of different countries.

This paper models the economic recession in the U.S. economy between 2007 and 2008 and its effects on two large economies (Japan and China) and three economic regions (the European Union, ASEAN and Latin America). We assume that the epicenter that is connected to all markets (country/region) is the GDP growth rate of the U.S.; at the same time, each market has a large number of windows refraction. Economic waves are generated first by plotting a single value (growth rate) in each window refraction and joining each single value located in each window refraction by straight lines from the epicenter to the last window refraction in each market (see Figure 2); we call this concept "windows refraction links (卢)". Windows refraction links (茕) facilitates the connection of all windows refraction in the same market and other markets simultaneously, from the epicenter to the last window refraction in the same market. Therefore, the epicenter is going to affect different countries simultaneously in the same graphical space but at different magnitudes and speeds. We assume that these countries maintain a high international trade volume and investment mobility relationship with the U.S. (Ruiz Estrada \& Yap, 2006). In this paper, the economic waves originate 
Table 2. The Economic Waves U.S., Japan, China, ASEAN, Latin America and Europe Union (2007-2008)

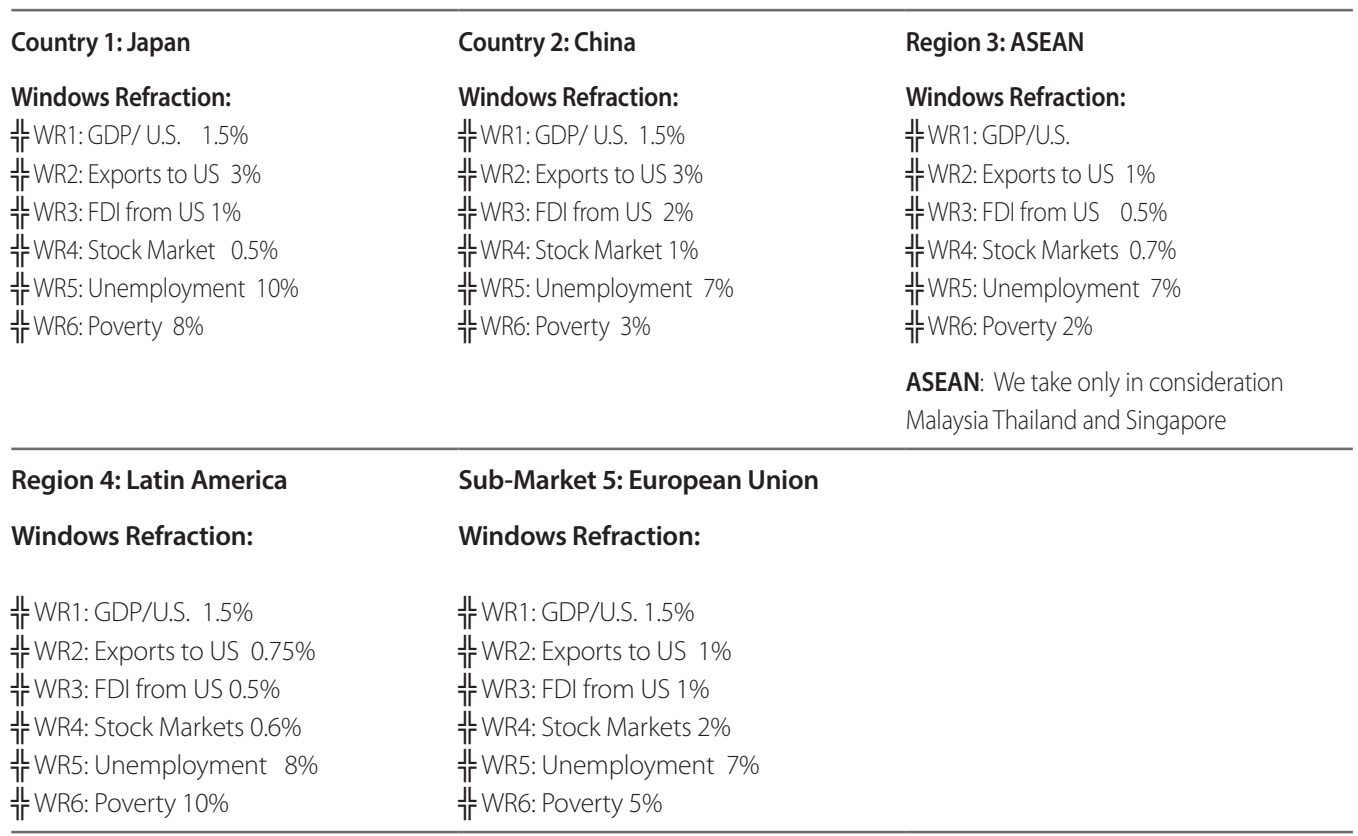

Note: The forecasting results are based on the application of the Mega-Space distributed lag model.

Statistical Sources: (Asian Development Bank [ADB], 2012; INTAL-IADB, 2012; European Union [EU], 2012; International Monetary Fund [IMF],2008; National Bureau of Economics Research [NBER], 2008; United Nations [UN], 2011; World Bank [WB], 2011)

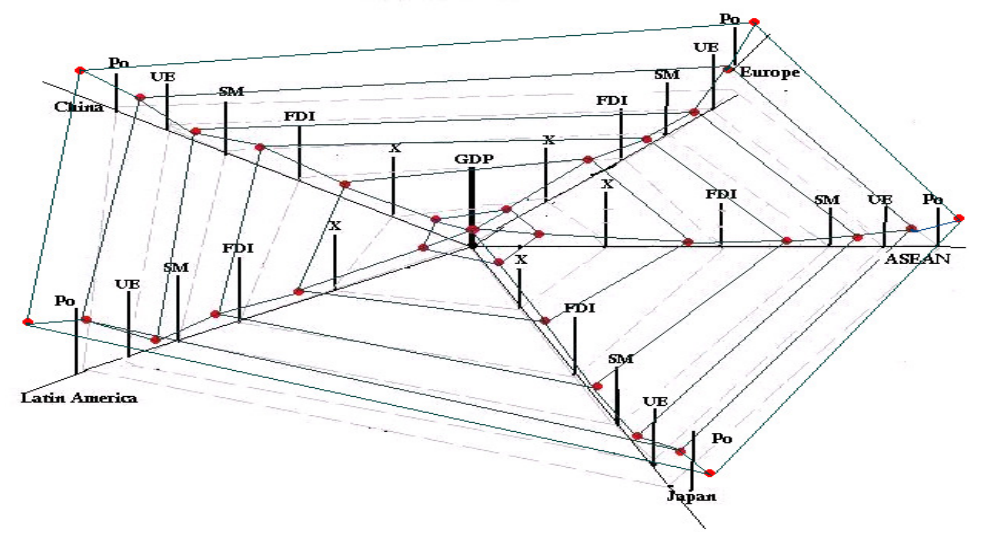

Figure 2. The Inter-Linkage Coordinate Space

GDP: Gross Domestic Product

FDI: Foreign Direct Investment

SM: Stock market

$\mathbf{X}$ : Exports

UE: Unemployment

Po: Poverty

Statistical Sources: : (ADB, 2012; INTAL-IADB, 2012; EU, 2012; IMF,2008; NBER, 2008; UN, 2011; WB, 2011) 
Table 3. Sub-Markets and Windows Refraction: The U.S. Economy (1929-2009)

\begin{tabular}{|c|c|c|}
\hline Sub-Market 1: Goods Market & Sub-Market 2: Money Market & Sub-Market 3: Social Market \\
\hline $\begin{array}{l}\text { Windows Refraction: } \\
\text { Windows Refraction 1: GDP } \\
\text { Windows Refraction 2: Interest Rate } \\
\text { Windows Refraction 3: Investment } \\
\text { Windows Refraction 4: Income }\end{array}$ & $\begin{array}{l}\text { Windows Refraction: } \\
\text { Windows Refraction 1: GDP } \\
\text { Windows Refraction 2: Interest Rate } \\
\text { Windows Refraction 3: Money: Supply and } \\
\text { Demand } \\
\text { Windows Refraction 4: Income }\end{array}$ & $\begin{array}{l}\text { Windows Refraction: } \\
\text { Windows Refraction 1: GDP } \\
\text { Windows Refraction 2: Education } \\
\text { Windows Refraction 3: Low-cost Housing } \\
\text { Windows Refraction 4: Health Care }\end{array}$ \\
\hline Sub-Market 4: Financial Market & $\begin{array}{l}\text { Sub-Market 5: International Trade } \\
\text { Market }\end{array}$ & Sub-Market 6: Labor Market \\
\hline Windows Refraction: & Windows Refraction: & Windows Refraction: \\
\hline $\begin{array}{l}\text { Windows Refraction 1: GDP } \\
\text { Windows Refraction 2: FDI } \\
\text { Windows Refraction 3: Bonds } \\
\text { Windows Refraction 4: Stock Market } \\
\text { Window Refraction 5: Real Estate }\end{array}$ & $\begin{array}{l}\text { Windows Refraction 1: GDP } \\
\text { Windows Refraction 2: Production } \\
\text { Windows Refraction 3: Exports and } \\
\text { Imports } \\
\text { Windows Refraction 4: Income }\end{array}$ & $\begin{array}{l}\text { Windows Refraction 1: GDP } \\
\text { Windows Refraction 2: Investment } \\
\text { Windows Refraction 3: Labor: } \\
\text { Supply and Demand } \\
\text { Windows Refraction 4: Unemployment } \\
\text { Window Refraction 5: Poverty }\end{array}$ \\
\hline $\begin{array}{l}\text { Sub-Market 7: Government } \\
\text { Market }\end{array}$ & $\begin{array}{l}\text { Sub-Market 8: Technological } \\
\text { Market }\end{array}$ & $\begin{array}{l}\text { Sub-Market 9: Transport and Energy } \\
\text { Market }\end{array}$ \\
\hline $\begin{array}{l}\text { Windows Refraction: } \\
\text { Windows Refraction 1: GDP } \\
\text { Windows Refraction 2: Taxes } \\
\text { Windows Refraction 3: Public } \\
\text { Investment } \\
\text { Windows Refraction 4: Fiscal Deficit }\end{array}$ & $\begin{array}{l}\text { Windows Refraction: } \\
\text { Windows Refraction 1: GDP } \\
\text { Windows Refraction 2: Investment } \\
\text { Windows Refraction 3: Productivity } \\
\text { Windows Refraction 4: Exports } \\
\text { Window Refraction 5: Income }\end{array}$ & $\begin{array}{l}\text { Windows Refraction: } \\
\text { Windows Refraction 1: GDP } \\
\text { Windows Refraction 2: Oil Prices } \\
\text { Windows Refraction 3: Energy Prices } \\
\text { Windows Refraction 4: Transport Costs }\end{array}$ \\
\hline
\end{tabular}

from the low GDP growth rate of the U.S. economy and spreads to the other world economies, significantly impacting the employment and poverty levels in all of the studied regions (see Figure 3). Figure 3 presents the economic waves, which show the growth of poverty between 2007-2008 in the U.S (10\%), Japan (8\%), European Union (5\%), China (3\%), ASEAN (2\%) and Latin America (12\%) (see Figure 3 and Table 3). These poverty rates indicate that the problem of poverty is not exclusive to developing and less developed countries (LDCs), as this visual tool shows poverty to be a global phenomenon. This conclusion is also supported by the fast and increasing expansion of global poverty that is sweeping much of the developed world, including the U.S, Japan and some members European Union, such as Spain, Portugal, Greece, Italy and Ireland, as a consequence of economic recession.
Given the tremendous influence that the GDP growth rate of the U.S. economy has on the performance and sustainability of markets in countries and regions around the world, it is important to identify some of the causes of slow GDP growth in the U.S. Some potential causes include a high budget deficit, high military spending, weak financial controls, China's competitive advantage and rapid economy expansion, a weak U.S. dollar, a large international trade deficit, a large amount of speculation in the real estate market, weak health and education programs, and the unstable behavior of oil prices in the international market. By defining the GDP growth rate of the U.S economy as the economic epicenter, the economic waves produced by our model can provide a clear illustration of how a global financial crisis can quickly spark a global poverty crisis (Hoyne, Miller, \& Schaller, 


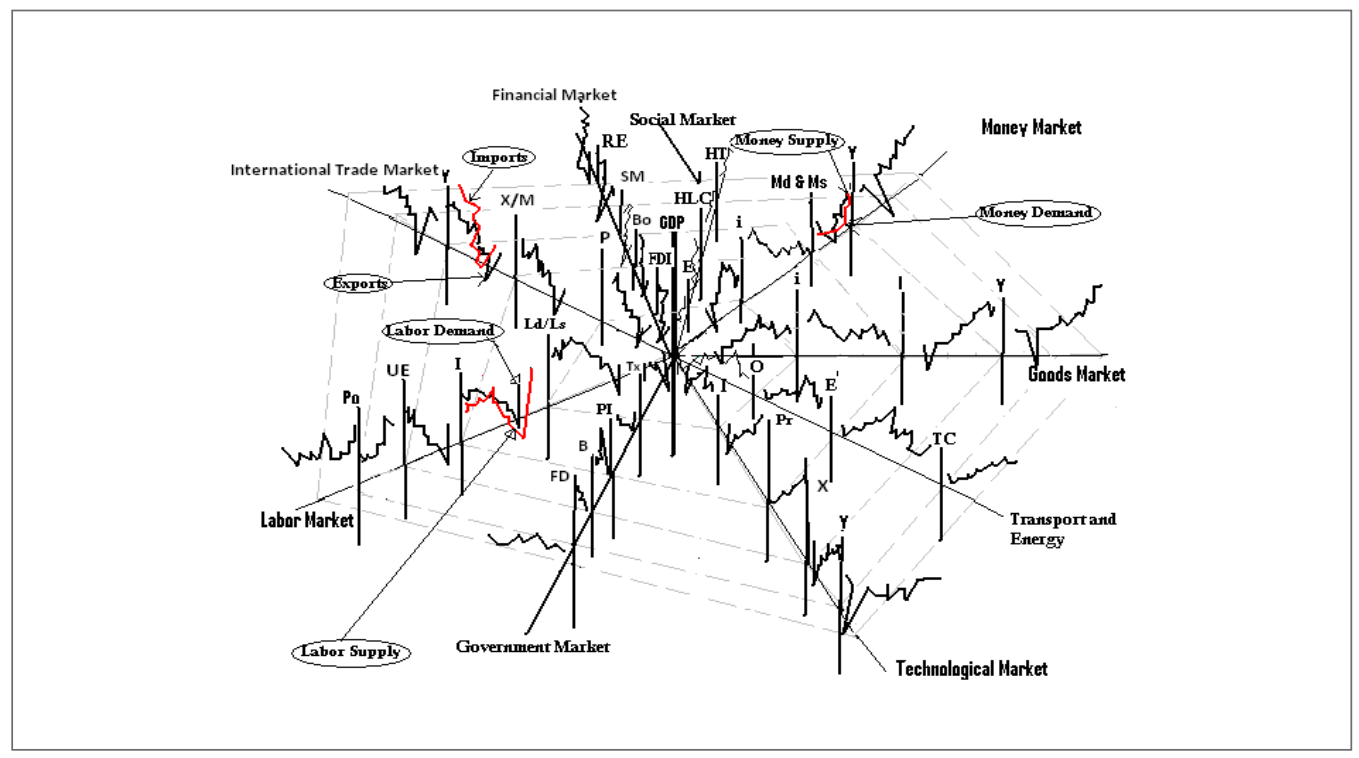

Figure 3. Economic Waves in 2007-2008

GDP: Gross Domestic Product

FDI: Foreign Direct Investment

SM: Stock market

$\mathbf{X}$ : Exports

UE: Unemployment

Po: Poverty

Statistical Sources: : (ADB, 2012; INTAL-IADB, 2012; EU, 2012; IMF,2008; NBER, 2008; UN, 2011; WB, 2011)

2012). In the same vein, this new type of graphical modeling offers to economists, policy makers, students and academics a multi-dimensional graphical modeling method for analyzing global economic recessions or crises (Ruiz Estrada, 2011b).

Next, we define the different types of times. First, partial times highlight time periods in which unexpected natural and uncontrolled economic events occur. Second, partial times can always be referenced against constant times: that is, every second, minute, hour, day, week, month and year that passes can be used as a reference. Third, evolutionary times are time periods anchored to certain real-world conditions rather than particular constant time periods. Fourth, general time is the aggregation of an infinite number of partial times, generating an infinite number of windows refraction or an infinite number of sub-markets.

We argue that the application of inter-linkage coordinate space and multi-dimensional graphical anima- tion can facilitate the understanding of the behavior and trends of complex economic phenomena. Through inter-linkage coordinate space and multi-dimensional graphical animation, the behavior of any economy as a whole can be observed both statically and dynamically in real time, as this method allows the observation of simultaneous co-variation of different variables. Thus, with this method, the failures of different sub-markets can be observed in the same graphical space, which may be valuable for the development of suitable policies to address economic crises or recessions in submarkets or in national markets.

Finally, this paper presents the development of the U.S. economy from 1929 to 2009 in a single graph, and this graph allows for the visualization of nine sub-markets and 40 windows refraction interacting in the same graphical space. This graph has 3,200 values plotted into 40 windows refraction located within nine sub-markets. These sub-markets comprise the 
goods sub-market, money sub-market, social submarket, financial sub-market, international trade sub-market, labor sub-market, government submarket, transport and energy sub-market and technological sub-market (see Table 3 and Figure 3). For the purposes of this study, we will not deeply analyze the U.S. economy, as we explore it only to display the U.S. economy within a multi-dimensional coordinate space under the use of different databases in different sub-markets (windows refraction). The application of the multi-dimensional coordinate space method offers a novel and useful multi-dimensional graphical modeling technique for economists, policy makers, students and academics.

\section{Comments and Remarks (from the reviewer)}

This paper shows how the interactions of the U.S. economy with five major economic regions, namely, Japan, China, ASEAN, Latin America, and the European Union, can be captured through use of the inter-linkage coordinate space. Such connections are graphically represented by placing the U.S. economy in the center and the other regions plotted along the rays (axes) that are drawn from the center, each ray having as many windows as are required at the predetermined perimeter levels. Each window has its own coordinate system, and all windows at each perimeter level are interconnected. Thus, variations within each economic region for each of the dimensions under scrutiny are plotted in the coordinate system of the refraction-windows. This scheme allows one to see the impact of the U.S. economy on other major economic regions as wave-like motions that originate in an epicenter that represents variation of the GDP growth rate of the U.S. economy. Because the economic data from the world as a whole are enormous in dimension, representing such data in a single visual graph may seem impossible; however, this can be accomplished if one draws rays from the origin, each for a given region, with as many refraction-windows as are required plotted on such rays in order to show the movement of the economy of each region. This method allows one to graph a complex set of data that cannot be represented in the conventional way, eliminating the worry of running out of axes or windows, as there is no limit to the number of rays and windows in this method. Thus, this paper demonstrates, through a particular example, that an inter-linkage coordinate space coupled with an accompanying graphing method of Econographicology is a powerful apparatus for representing complex sets of data.

\section{References}

Asian Development Bank (2012). General Information and Database Statistics. Available at www.adb.org

European Union (2012). General Information and Database Statistics. Available at www.eu.eu

Hoyne, H., Miller, D., \& Schaller, J. (2012). Who Suffers During Recession? The journal of Economic Perspective, 26 (3), 27-47.

INTAL-IADB. (2012). General Information and Database Statistics. Available at http://www.iadb.org/ en/intal/intal-home,1081.html

International Monetary Fund (2008). General Information and Database Statistics. Available at http://www.imf.org

Inselberg, A., \& Dimsdale, B. (1994). Multidimensional Lines II: Proximity and Applications. SIAM Journal on Applied Mathematics, 54 (2), 578-596.

Issing, O. (2011). The Crisis of European Monetary Union - Lessons to be Drawn. Journal of Policy Modeling, 33 (5), 737-749.

National Bureau of Economic Research (2008). Statistics Database. Available at www.nber.org

Ruiz Estrada, M. A. \& Yap, S. F. (2006). The Openness Growth Monitoring Model (OGM-Model). Journal of Policy Modeling, 28 (3), 235-246.

Ruiz Estrada, M. A. (2007). Econographicology. International Journal of Economic Research, 4 (1), 75-86.

Ruiz Estrada, M.A. (2011a). Multidimensional Coordinate Spaces. International Journal of Physical Sciences, 6 (3), 340-357.

Ruiz Estrada, M.A. (2011b). Policy modelling: Definition, Classification, and Evaluation. Journal of Policy Modeling, 33 (4), 523-536.

Ruiz Estrada, M. A. (2012). A New Multidimensional Graphical Approach for Mathematics and Physics. Malaysian Journal of Sciences, 31 (2), 175-198.

Ruiz Estrada, M. A., \& Yap, S. F. (2013). The Origins and Evolution of Policy Modeling, Journal of Policy Modeling, 34 (1), 170-182. 
Ruiz Estrada, M. A., Yap, S. F. \& Park, D. (2014). Applying the natural disasters vulnerability evaluation model to the March 2011 north-east Japan earthquake and tsunami. [Special Issue: The 2011 Great East Japan Earthquake] Disasters, 38 (s2): s206-s229.

Shchepin, E.V. (1976). Topology of limit spaces with uncountable inverse spectra. Uspekhi Matematicheskikh Nauk, 31 (5-191), 191 - 226.

United Nations (2011). General Information and Database Statistics. Retrieved from: www.un.org

World Bank (2011). General Information and Database Statistics. Available at www.worldbank.org 
